\title{
Depletable Peroxidase-like Activity of Fe304 Nanozymes Accompanied with Phase Transformation Triggered by Separate Migration of Electron and Iron Ion
}

\author{
Yu Zhang ( $\nabla$ zhangyu@seu.edu.cn ) \\ Southeast University \\ Haijiao Dong \\ Southeast University \\ Wei Du \\ Southeast University \\ Jian Dong \\ Southeast University \\ Fei Kong \\ Southeast University \\ Wenlong Cheng \\ Monash University https://orcid.org/0000-0002-2346-4970 \\ Ming Ma \\ Southeast University \\ Ning Gu \\ Southeast University https://orcid.org/0000-0003-0047-337X
}

Article

Keywords:

Posted Date: January 24th, 2022

DOI: https://doi.org/10.21203/rs.3.rs-1270819/v1

License: (c) (1) This work is licensed under a Creative Commons Attribution 4.0 International License. Read Full License 
The Depletable Peroxidase-like Activity of $\mathrm{Fe}_{3} \mathrm{O}_{4}$ Nanozymes Accompanied with Phase Transformation Triggered by Separate Migration of Electrons and Iron Ions

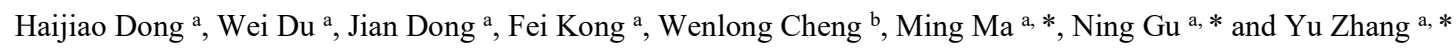

a State Key Laboratory of Bioelectronics, Jiangsu Key Laboratory for Biomaterials and Devices, School of Biological Science and Medical Engineering \& Collaborative Innovation Center of Suzhou Nano Science and Technology, Southeast University, Nanjing 210096, P. R. China

${ }^{b}$ Department of Chemical Engineering, Faculty of Engineering, Monash University, Clayton, Victoria, Australia. The Melbourne Centre for Nanofabrication, Clayton, Victoria, Australia.

* Corresponding author:

Yu Zhang, Ph.D Professor

Ning Gu, Ph.D Professor

Ming Ma, Ph.D Associate professor

State Key Laboratory of Bioelectronics, Jiangsu Key Laboratory for Biomaterials and Devices,

School of Biological Science and Medical Engineering, Southeast University

87 Dingjiaqiao, District Gulou, Nanjing 210009, China

Tel: (86) 25-8327 2496.

E-mail:zhangyu@seu.edu.cn; guning@seu.edu.cn;maming@seu.edu.cn 


\section{Abstract}

As the pioneering $\mathrm{Fe}_{3} \mathrm{O}_{4}$ nanozymes, their explicit peroxidase (POD)-like catalytic mechanism remains elusive. Although many studies have proposed the surface $\mathrm{Fe}^{2+}$-induced Fenton-like reactions accounting for their POD-like activity, few focus on the internal atomic changes and their contribution to the catalytic reaction. Here we report that $\mathrm{Fe}^{2+}$ within $\mathrm{Fe}_{3} \mathrm{O}_{4}$ transfers electrons to the surface via the $\mathrm{Fe}^{2+}-\mathrm{O}-\mathrm{Fe}^{3+}$ chain, regenerating the surface $\mathrm{Fe}^{2+}$ and enabling a sustained POD-like catalytic reaction. This process occurs with the outward migration of excess oxidized $\mathrm{Fe}^{3+}$ from the lattice, which is a rate-limiting step. After prolonged catalysis, $\mathrm{Fe}_{3} \mathrm{O}_{4}$ nanozymes suffer the phase transformation to $\gamma-\mathrm{Fe}_{2} \mathrm{O}_{3}$ with a depletable POD-like activity. This self-depleting characteristic of nanozymes with internal atoms involved in electrons transfer and ion migration is well-validated on lithium iron phosphate nanoparticles. We reveal a key yet ever ignored issue concerning the necessity of considering both surface and internal atoms when designing, modulating, and applying nanozymes. 


\section{Introduction}

Since the first discovery of $\mathrm{Fe}_{3} \mathrm{O}_{4}$ nanoparticels (NPs) with intrinsic peroxidase (POD)-like activity in 2007, nanomaterial-based artificial enzymes (nanozymes) and their extensive applications have rapidly attracted attention over the past decade. ${ }^{1-10}$ Recently, the research efforts on nanozymes have gradually shifted from application-oriented to mechanism-oriented, as a well-defined mechanism is the key to design, modulate, and apply the catalytic properties of nanozymes. ${ }^{11-15}$ Given the intricate structure-activity relationships and restricted characterization techniques, however, fewer breakthroughs have been made in understanding the explicit mechanism of most nanozymes. ${ }^{3,4}$

Despite being a pioneering nanozyme, research on the catalytic mechanism of the POD-like activity of $\mathrm{Fe}_{3} \mathrm{O}_{4}$ NPs is still limited. ${ }^{10,14-19}$ To date, it is generally accepted that high-reactive hydroxyl radicals $(\cdot \mathrm{OH})$ generated by Fenton-like reactions (Equation 1-2) involving the surface $\mathrm{Fe}^{2+}$ under acid conditions contributes to the POD-like activity of $\mathrm{Fe}_{3} \mathrm{O}_{4}$ NPs. ${ }^{18,19}$ Similar to natural horseradish peroxidase (HRP), $\mathrm{Fe}_{3} \mathrm{O}_{4}$ nanozymes follow the ping-pong mechanism and Michaelis-Menten kinetics. ${ }^{10}$ Besides, their catalytic performances are influenced by particles size, morphology, lattice structure, doping, surface modification, substrates used, as well as the catalytic environment exposed, all of which could affect the surface active sites by altering the surface chemistry. ${ }^{10,16,17,20-23}$ Other individual studies have investigated the absorption, activation, and desorption processes of substrates (e.g. $\mathrm{H}_{2} \mathrm{O}_{2}$ and TMB) on the surface of $\mathrm{Fe}_{3} \mathrm{O}_{4}$ at the atomic level based on density functional theory and developed some descriptors to predict their POD-like activity. ${ }^{14,15}$

$$
\mathrm{Fe}^{2+}+\mathrm{H}_{2} \mathrm{O}_{2} \rightarrow \mathrm{Fe}^{3+}+\cdot \mathrm{OH}+\mathrm{OH}^{-} \quad k_{1}=76(\mathrm{~mol} / \mathrm{L})^{-1} \mathrm{~s}^{-1}
$$




$$
\mathrm{Fe}^{3+}+\mathrm{H}_{2} \mathrm{O}_{2} \rightarrow \mathrm{Fe}^{2+}+\cdot \mathrm{OOH}+\mathrm{H}^{+} \quad k_{2}=0.002(\mathrm{~mol} / \mathrm{L})^{-1} \mathrm{~s}^{-1}
$$

The above mechanistic studies share a theoretical premise: only the surface-active sites play a decisive role in the enzymatic-like property of nanozymes since catalysis occurs mainly on the particle surface or interface. This view is now widely recognized and works for most types of nanozymes. ${ }^{1,2,4,11,23,24}$ For example, in a recent controversial question regarding how to define "nanozyme concentration", Liu et al. argued that considering the whole particle or all atomic units within a particle as an enzyme unit would overestimate and underestimate the catalytic activity of nanozymes, respectively, because it is the surface atoms that are really the catalytic active sites. ${ }^{24}$ However, in the Fenton-like reactions triggered by $\mathrm{Fe}_{3} \mathrm{O}_{4}$ nanozymes, we noticed that the reaction rate constant of Equation (1) is much higher than that of Equation (2), which implies that the surface-active $\mathrm{Fe}^{2+}$ is hardly recovered after being oxidized. This irreversible oxidation of surface $\mathrm{Fe}^{2+}$ prompts us to ponder if only the surface atoms of the nanozymes, particularly for metal oxide nanozymes, act in enzymatic-like catalysis, would these active sites be exhausted after long-term catalysis, rendering the nanozymes inactive? So far, nevertheless, no relevant studies can conclusively answer this crucial question.

Here we propose a key yet ever ignored issue regarding the POD-like mechanism of nanozymes by characterizing the chemical composition and catalytic activity of the recycled $\mathrm{Fe}_{3} \mathrm{O}_{4} \mathrm{NPs}$ participating in cyclic POD-like catalysis. Both surface and interior $\mathrm{Fe}^{2+}$ were found to impart POD-like property to $\mathrm{Fe}_{3} \mathrm{O}_{4}$ nanozymes. Namely, $\mathrm{Fe}^{2+}$ inside the particle transfers its electron to the surface layer, regenerating the surface $\mathrm{Fe}^{2+}$ and sustaining the catalytic reaction. This process is coupled with the outward migration of excess oxidized $\mathrm{Fe}^{3+}$, 
which is a rate-limiting step. As the catalysis continues, $\mathrm{Fe}_{3} \mathrm{O}_{4}$ is slowly oxidized into $\gamma-\mathrm{Fe}_{2} \mathrm{O}_{3}$ accompanying the depleted enzyme-like activity, similar to the conventional low-temperature oxidation of magnetite, only with different electron receptors. This self-depleting characteristic of nanozymes with internal atoms involved in electrons transfer and ion migration is further demonstrated by a typical model material, $\mathrm{LiFePO}_{4}$, which contains the redox-active metal sites and mobile lithium ions $\left(\mathrm{Li}^{+}\right)$encapsulated in a rigid phosphate network. This paper reveals that internal atoms may also contribute to the nanozyme-catalyzed reactions even though these reactions occur on the surface of NPs, which is thought-provoking when designing, regulating, and applying nanozymes.

\section{Results}

Synthesis and Characterization of IONPs. Near-spherical magnetite nanoparticles $\left(\mathrm{Fe}_{3} \mathrm{O}_{4}\right.$ NPs) with an average diameter of $10.16 \pm 0.12 \mathrm{~nm}$ (Supplementary Fig. 1a) were synthesized using the chemical co-precipitation method. ${ }^{18}$ Maghemite $\left(\gamma-\mathrm{Fe}_{2} \mathrm{O}_{3}\right)$ and hematite $\left(\alpha-\mathrm{Fe}_{2} \mathrm{O}_{3}\right)$ NPs were derived by calcining the $\mathrm{Fe}_{3} \mathrm{O}_{4}$ NPs powder at $200{ }^{\circ} \mathrm{C}$ and $650{ }^{\circ} \mathrm{C}$ for 2 hours, respectively (Fig. 1a). XRD and Raman spectra (Supplementary Fig. 1b-c) show the successful synthesis of these three iron oxide NPs (IONPs). These IONPs were uniformly dispersed in an aqueous solution at $\mathrm{pH}$ of 3 by ultrasonication (Supplementary Fig. 1d). To avoid affecting the enzymatic-like activity, all particles were free of the surface coating. Their POD-like activities were assessed using different colorimetric substrates, including TMB, ABTS, and OPD, in the presence of $\mathrm{H}_{2} \mathrm{O}_{2}$. The results show that their catalytic activity followed the order of $\mathrm{Fe}_{3} \mathrm{O}_{4} \mathrm{NPs}>>\gamma-\mathrm{Fe}_{2} \mathrm{O}_{3} \mathrm{NPs}>\alpha-\mathrm{Fe}_{2} \mathrm{O}_{3} \mathrm{NPs}$ (Supplementary Fig. 2). To 
better quantify their POD-like activity, we calculated their specific activity $\left(a_{\text {nano }}\right)$ according to the specified method, ${ }^{26,27}$ which were $1.79,0.44$, and $0.03 \mathrm{U} \cdot \mathrm{mg}^{-1}$, respectively (Fig. 1b). As previously reported, ${ }^{10,18}$ the higher catalytic ability of $\mathrm{Fe}_{3} \mathrm{O}_{4} \mathrm{NPs}$ originates from the Fenton-like reaction triggered by the surface $\mathrm{Fe}^{2+}$ (Supplementary Fig. 3). The negligible $a_{\text {nano }}$ of $\alpha-\mathrm{Fe}_{2} \mathrm{O}_{3} \mathrm{NPs}$ compared with $\gamma-\mathrm{Fe}_{2} \mathrm{O}_{3}$ NPs is ascribed to the change of the inverse spinel structure due to the higher calcination temperature.

a

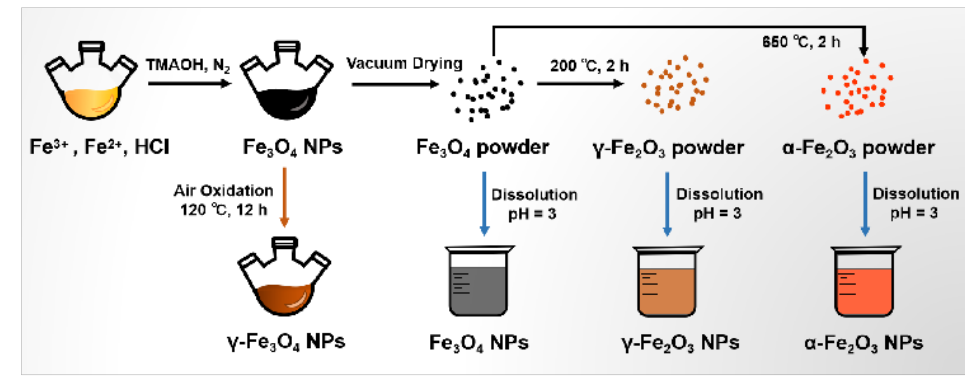

c

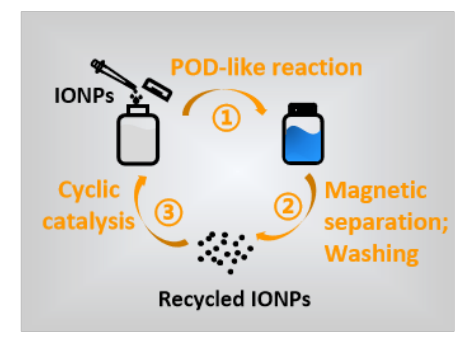

f

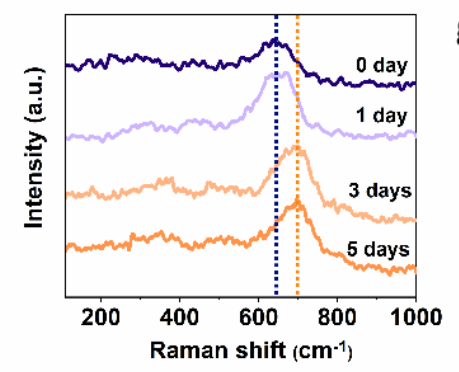

d

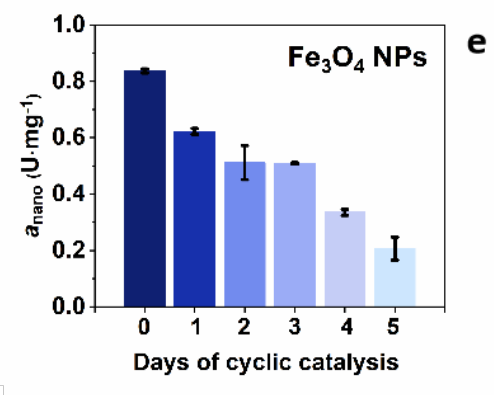

g

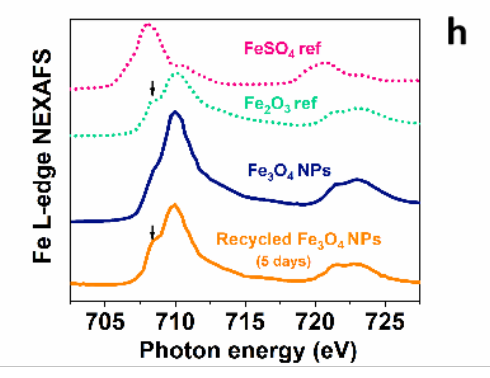

h
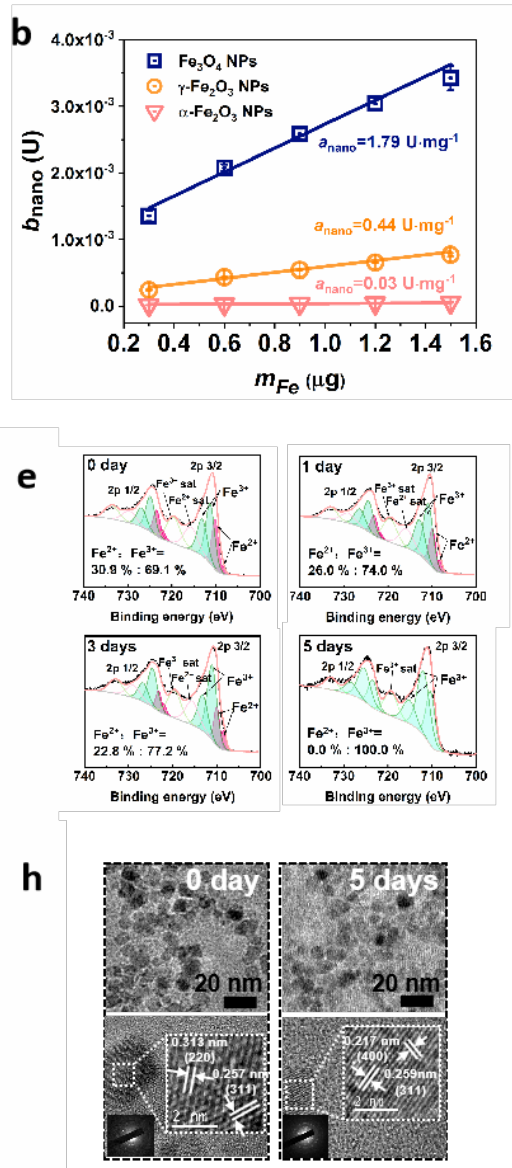

Fig. 1 The synthesis of IONPs and cyclic POD-like catalysis. (a) Illustration of the synthesis process of IONPs. (b) The specific activity $\left(a_{\text {nano }}\right)$ of these three IONPs with TMB as colorimetric substrates. (c) Diagram of the cyclic catalysis assay. (d) Kinetic study of $a_{\text {nano }}$ values of $\mathrm{Fe}_{3} \mathrm{O}_{4}$ NPs with the days of cyclic catalytic reaction. (e) The fitted Fe2p XPS spectra and (f) Raman spectra of $\mathrm{Fe}_{3} \mathrm{O}_{4}$ NPs recycled after catalysis on days $0,1,3$, and 5. (g) The Fe L-edge 
NEXAFS spectra of $\mathrm{Fe}_{3} \mathrm{O}_{4}$ NPs and recycled $\mathrm{Fe}_{3} \mathrm{O}_{4}$ NPs after 5 days of catalysis. Dotted lines represent the reference spectra of $\mathrm{FeSO}_{4}$ and $\mathrm{Fe}_{2} \mathrm{O}_{3}$ powder. (h) TEM and HRTEM images of $\mathrm{Fe}_{3} \mathrm{O}_{4}$ NPs and recycled $\mathrm{Fe}_{3} \mathrm{O}_{4}$ NPs after 5 days of catalysis. Inset: the corresponding SAED pattern.

Cyclic POD-like catalysis of $\mathrm{Fe}_{3} \mathrm{O}_{4}$ NPs. To investigate whether the surface $\mathrm{Fe}^{2+}$ of $\mathrm{Fe}_{3} \mathrm{O}_{4}$ NPs is depleted after participating in prolonged catalysis, we continuously increased the amount of substrate TMB under sufficient $\mathrm{H}_{2} \mathrm{O}_{2}$ with as-synthesized three IONPs as "continuous catalysts", and monitored the absorbance changes of TMB oxidation products at $650 \mathrm{~nm}$ within 12 h. From Supplementary Fig. 4, even though the TMB was increased from $0.087 \mathrm{mM}$ to $0.52 \mathrm{mM}$, the $\mathrm{Fe}_{3} \mathrm{O}_{4} \mathrm{NPs}$ were still able to continuously and rapidly engage in the catalytic reaction for a long duration ( $\geq 12 \mathrm{~h}$ ) without showing signs of depletion. We speculated two reasons: 1) the amount of substrate is still too low to completely consume the surface-active $\left.\mathrm{Fe}^{2+} ; 2\right)$ The $\mathrm{Fe}^{2+}$ within $\mathrm{Fe}_{3} \mathrm{O}_{4}$ NPs provides the impetus for the continuous catalysis.

Cyclic POD-like catalytic assays (Fig. 1c) were carried out as validation, which could provide sufficient substrates for $\mathrm{Fe}_{3} \mathrm{O}_{4}$ NPs to keep exerting their POD-like capacity. We evaluated the $a_{\text {nano }}$ of the recycled $\mathrm{Fe}_{3} \mathrm{O}_{4}$ NPs within five days. The results show that the catalytic ability of $\mathrm{Fe}_{3} \mathrm{O}_{4}$ NPs decreased to a level comparable to that of $\gamma$ - $\mathrm{Fe}_{2} \mathrm{O}_{3}$ NPs after five days of cyclic catalysis, while the changes of $\gamma-\mathrm{Fe}_{2} \mathrm{O}_{3} \mathrm{NPs}$ were negligible (Fig. 1d and Supplementary Fig. 5). It pushed us to wonder how the surface-active $\mathrm{Fe}^{2+}$ of $\mathrm{Fe}_{3} \mathrm{O}_{4} \mathrm{NPs}$ alone could sustain the TMB oxidation up to 100 hours? Conceivably, if only the surface-active sites are responsible for the enzyme-like performance, nanozymes will 
deactivate when the surface-active sites are exhausted.

To reveal the potential reasons for the sustained catalytic capacity of $\mathrm{Fe}_{3} \mathrm{O}_{4} \mathrm{NPs}$, we characterized the physicochemical properties of the recycled $\mathrm{Fe}_{3} \mathrm{O}_{4}$ NPs using different methodologies. The chemical states of $\mathrm{Fe}$ atoms in $\mathrm{Fe}_{3} \mathrm{O}_{4} \mathrm{NPs}$ recycled from catalysis at days $0,1,3$, and 5 were first analyzed by XPS technology. The X-ray penetration depth of the analyzed sample ranges from 2 to10 $\mathrm{nm}$. Since the average diameter of as-synthesized $\mathrm{Fe}_{3} \mathrm{O}_{4}$ NPs is around $10 \mathrm{~nm}$, the Fe valence state obtained from the Fe2p fitting analysis can be approximated as the oxidation state of individual $\mathrm{Fe}_{3} \mathrm{O}_{4} \mathrm{NPs}$. As shown in Fig. 1e, the $\mathrm{Fe}^{2+}$ in $\mathrm{Fe}_{3} \mathrm{O}_{4}$ NPs decreased from the original $30.9 \%$ to $0 \%$ with the increase of cyclic catalytic days, indicating that the interior $\mathrm{Fe}^{2+}$ was also oxidized to $\mathrm{Fe}^{3+}$ in the successive POD-like reactions. Furthermore, in the Raman spectra of the recycled $\mathrm{Fe}_{3} \mathrm{O}_{4} \mathrm{NPs}$, the feature of the $A_{1 \mathrm{~g}}$ mode band shifted from $660 \mathrm{~cm}^{-1}$ to $700 \mathrm{~cm}^{-1}$, corresponding to a transition from magnetite to maghemite (Fig. 1f). ${ }^{28,29}$ Besides, this phase transformation was also confirmed by the NEXAFS spectroscopy. Figure 1g shows the Fe L-edge NEXAFS spectra of the control $\mathrm{Fe}_{3} \mathrm{O}_{4}$ NPs and the recycled $\mathrm{Fe}_{3} \mathrm{O}_{4}$ NPs after 5 days of catalysis, in comparison with two reference spectra of $\mathrm{FeSO}_{4}$ and $\mathrm{Fe}_{2} \mathrm{O}_{3}$. The increased splitting $\mathrm{L}_{3}$ peak near $708 \mathrm{eV}$ for the recycled $\mathrm{Fe}_{3} \mathrm{O}_{4}$ NPs coincides with reference $\mathrm{Fe}_{2} \mathrm{O}_{3} \cdot{ }^{30-32}$ Additionally, TEM images (Fig. 1h) and XRD pattern (Supplementary Fig. 6) show that the influence of this transformation on the particle morphology, size, and lattice structure is negligible. Based on these characterization results, we conclude that both surface and internal $\mathrm{Fe}^{2+}$ can be oxidized into $\mathrm{Fe}^{3+}$ accompanied by a gradual phase transformation to $\gamma-\mathrm{Fe}_{2} \mathrm{O}_{3}$ during $\mathrm{Fe}_{3} \mathrm{O}_{4}$ nanozymes exerting their POD-like activity. 
Aeration oxidation kinetics of $\mathrm{Fe}_{3} \mathrm{O}_{4}$ NPs. We assume that the oxidation of $\mathrm{Fe}_{3} \mathrm{O}_{4}$ nanozymes induced by POD-like catalysis is comparable to the traditional low-temperature $\left(<200{ }^{\circ} \mathrm{C}\right)$ air oxidation of magnetite since the crystal structure of both remains unchanged during the oxidation process. ${ }^{33}$ Both magnetite and maghemite contain $32 \mathrm{O}$ atoms per unit cell. The difference is that the former contains $24 \mathrm{Fe}$ atoms $\left(16 \mathrm{Fe}^{3+}\right.$ and $\left.8 \mathrm{Fe}^{2+}\right)$, while the latter has only $21.33 \mathrm{Fe}$ atoms $\left(\right.$ all $\mathrm{Fe}^{3+}$ ). Namely, once $8 \mathrm{Fe}^{2+}$ in magnetite are oxidized to $8 \mathrm{Fe}^{3+}$ releasing 8 electrons, a charge imbalance will occur (Equation 3). To maintain electroneutrality, $2.67 \mathrm{Fe}^{3+}$ have to migrate to the crystal surface, leaving the cation vacancy (Equation 4). ${ }^{34}$ The outward moving $\mathrm{Fe}^{3+}$ will coordinate with the surface absorbed $\mathrm{O}^{2-}$ which is ionized by the electrons generated by the oxidation of $\mathrm{Fe}^{2+}$. Therefore, the phase transformation of $\mathrm{Fe}_{3} \mathrm{O}_{4}$ to $\gamma-\mathrm{Fe}_{2} \mathrm{O}_{3}$ is a single-phase topological reaction accompanied with the separate migration of electrons and excess $\mathrm{Fe}^{3+} \cdot 34$

$$
\begin{gathered}
\mathrm{Fe}_{16}(\mathrm{III}) \mathrm{Fe}_{8}(\mathrm{II}) \mathrm{O}_{32} \rightarrow \mathrm{Fe}_{24}(\mathrm{III}) \mathrm{O}_{32}{ }^{+8}+8 \mathrm{e}^{-} \\
\mathrm{Fe}_{24}(\mathrm{III}) \mathrm{O}_{32}{ }^{+8} \rightarrow \gamma-\mathrm{Fe}_{21.33}(\mathrm{III}) \square_{2.67} \mathrm{O}_{32}+2.67 \mathrm{Fe}(\mathrm{III})
\end{gathered}
$$

Lattice defects have been reported to facilitate the outward migration of excess iron ions, thereby accelerating the oxidation process of magnetite. ${ }^{35}$ As verification, we compared the aeration oxidation kinetics of $\mathrm{Fe}_{3} \mathrm{O}_{4}$ NPs synthesized by two methods with different levels of lattice defects. One was prepared by the chemical co-precipitation method as described above (Fig. 1a), which is considered to possess more lattice defects (named cc- $\mathrm{Fe}_{3} \mathrm{O}_{4} \mathrm{NPs}$ ). The other was prepared by the thermal decomposition method (Supplementary Fig. 7) with a relatively complete lattice structure (named TD- $\mathrm{Fe}_{3} \mathrm{O}_{4} \mathrm{NPs}$ ) ${ }^{36}$ Both $\mathrm{Fe}_{3} \mathrm{O}_{4} \mathrm{NPs}$ have a similar 
average particle size $(\sim 10 \mathrm{~nm})$ without surface coating. Their aqueous solutions were stirred under the same aeration rate (with air) for $12 \mathrm{~h}$ at $120{ }^{\circ} \mathrm{C}$. For a better comparison, the oxidation system of $\mathrm{cc}-\mathrm{Fe}_{3} \mathrm{O}_{4} \mathrm{NPs}$ (total $170 \mathrm{~mL}, 3.6 \mathrm{mg} \mathrm{Fe} / \mathrm{mL}$ ) was much larger than that of TD- $\mathrm{Fe}_{3} \mathrm{O}_{4} \mathrm{NPs}$ (total $30 \mathrm{~mL}, 0.45 \mathrm{mg} \mathrm{Fe} / \mathrm{mL}$ ). This implies that individual TD- $\mathrm{Fe}_{3} \mathrm{O}_{4}$ could gain more oxygen than cc- $\mathrm{Fe}_{3} \mathrm{O}_{4}$ to keep it oxidized. From Fig. 2a-b, both $\mathrm{Fe}_{3} \mathrm{O}_{4} \mathrm{NPs}$ exhibited electronic transitions in the visible and NIR region due to intervalence charge transfer between $\mathrm{Fe}^{2+}$ and $\mathrm{Fe}^{3+},{ }^{37}$ which decreased gradually with oxidation time. At the end of aeration oxidation, little absorption beyond $700 \mathrm{~nm}$ was observed, indicating a phase transformation from $\mathrm{Fe}_{3} \mathrm{O}_{4} \mathrm{NPs}$ to $\gamma-\mathrm{Fe}_{2} \mathrm{O}_{3} \mathrm{NPs} .{ }^{37}$ Besides, the color of both suspensions gradually changed from dark-brown to reddish-brown. Notably, despite the less oxygen exposure for individual $\mathrm{cc}-\mathrm{Fe}_{3} \mathrm{O}_{4} \mathrm{NP}$, its NIR absorption decreased faster than that of TD- $\mathrm{Fe}_{3} \mathrm{O}_{4} \mathrm{NP}$, especially during the initial oxidation phase (within three hours). These results confirm that more lattice defects favor the oxidation reaction of $\mathrm{Fe}_{3} \mathrm{O}_{4} \mathrm{NPs}$ due to the faster electron and ion transfer.

Analogous to aerated oxidation, the rapid electron and ion migration also facilitates the POD-like catalysis of $\mathrm{Fe}_{3} \mathrm{O}_{4} \mathrm{NPs}$, with the only difference that the electron receptor changed from $\mathrm{O}_{2}$ in aerated oxidation reaction to $\mathrm{H}_{2} \mathrm{O}_{2}$ in POD-like reaction. To prove this, the POD-like activity of cc- $\mathrm{Fe}_{3} \mathrm{O}_{4} \mathrm{NPs}$ and TD- $\mathrm{Fe}_{3} \mathrm{O}_{4} \mathrm{NPs}$ as well as their variation with aerated oxidation time were investigated. As seen in Supplementary Fig. 8, the POD-like activity of cc- $\mathrm{Fe}_{3} \mathrm{O}_{4} \mathrm{NPs}$ was higher (2.8 folds) than that of $\mathrm{TD}-\mathrm{Fe}_{3} \mathrm{O}_{4} \mathrm{NPs}$, despite $\mathrm{TD}-\mathrm{Fe}_{3} \mathrm{O}_{4} \mathrm{NPs}$ having a smaller hydrodynamic diameter and negative surface potential contributing to a strong affinity with TMB. Aeration oxidation kinetic studies show that the POD-like activity 
of both $\mathrm{Fe}_{3} \mathrm{O}_{4}$ NPs decreased with oxidation time (Fig. 2c), along with slight fluctuations in hydrodynamic size and surface potential (Supplementary Fig. 9). However, the decline rate of cc- $\mathrm{Fe}_{3} \mathrm{O}_{4}$ NPs was faster than TD- $\mathrm{Fe}_{3} \mathrm{O}_{4} \mathrm{NPs}$, particularly in the initial oxidation stage. This phenomenon is consistent with the changes of NIR spectra shown in Fig. 2a-b. These results further confirm that the more lattice defects of $\mathrm{Fe}_{3} \mathrm{O}_{4} \mathrm{NPs}$, the easier the migration of excess Fe ions, and thus the higher the POD-like activity. It also means that $\mathrm{Fe}_{3} \mathrm{O}_{4} \mathrm{NPs}$ with more defect sites are easier to be depleted when involved in a POD-like reaction due to their excellent catalytic capability.
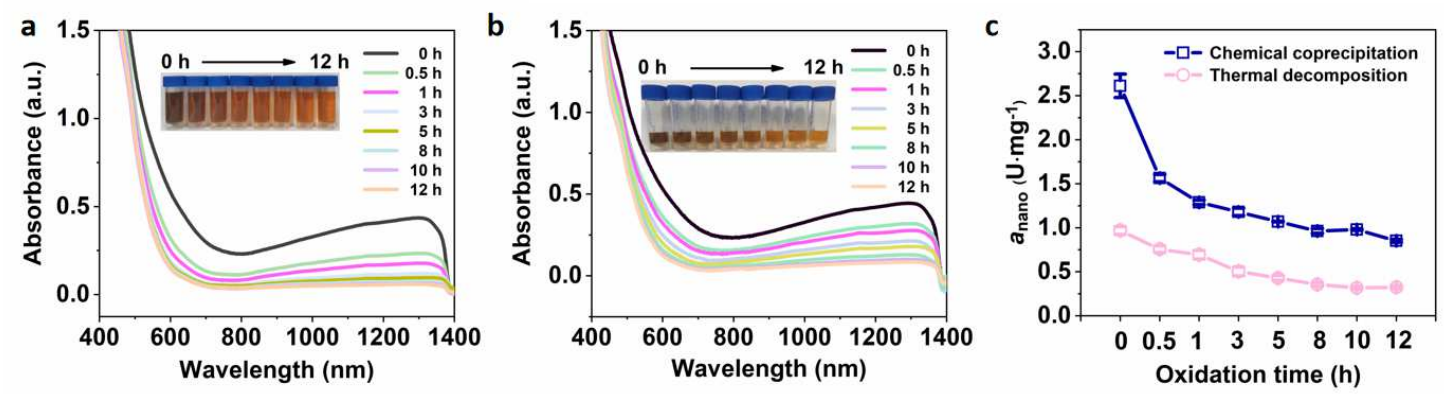

Fig. 2 The aeration oxidization kinetics of $\mathrm{Fe}_{3} \mathrm{O}_{4}$ NPs. Variation of UV-vis-NIR absorption of (a) cc- $\mathrm{Fe}_{3} \mathrm{O}_{4}$ NPs and (b) TD- $\mathrm{Fe}_{3} \mathrm{O}_{4}$ NPs with aeration oxidation time. Insets are photos of the suspensions corresponding to oxidation times at $0,0.5,1,3,5,8,10$, and $12 \mathrm{~h}$. All spectra and photos were obtained at the same Fe concentration. (c) Changes in $a_{\text {nano }}$ of the oxidized cc- $-\mathrm{Fe}_{3} \mathrm{O}_{4}$ NPs and TD- $\mathrm{Fe}_{3} \mathrm{O}_{4} \mathrm{NPs}$ during the aeration oxidation.

Catalytic mechanism of the POD-like for $\mathrm{Fe}_{3} \mathrm{O}_{4}$ NPs. Taken together, the catalytic mechanism of the POD-like activity for $\mathrm{Fe}_{3} \mathrm{O}_{4}$ NPs can be summarized as follows (Fig. 3): 1) Fenton-like reaction on the surface. Firstly, $\mathrm{H}_{2} \mathrm{O}_{2}$ adsorbed on the surface of particles accept electrons from the surface $\mathrm{Fe}^{2+}$, and then dissociates into highly active $\cdot \mathrm{OH}$ to oxidize the substrates. The surface $\mathrm{Fe}^{2+}$ is oxidized to $\left.\mathrm{Fe}^{3+} ; 2\right)$ Internal electrons transfer. Then, the adjacent $\mathrm{Fe}^{2+}$ inside the surface transfers its electron to the surface $\mathrm{Fe}^{3+}$ via the $\mathrm{Fe}^{2+}-\mathrm{O}-\mathrm{Fe}^{3+}$ 
chain, retrieving the surface $\mathrm{Fe}^{2+}$ and providing the dynamics for the sustained catalytic reaction; 3) Excess Fe ions outward migration. With the in-situ oxidation of internal $\mathrm{Fe}^{2+}$, to maintain electroneutrality, the excess $\mathrm{Fe}^{3+}$ in the lattice migrate outward to the surface, leaving cation vacancies; 4) Chemical composition change. With the continuous POD-like catalytic reaction, $\mathrm{Fe}_{3} \mathrm{O}_{4} \mathrm{NPs}$ are oxidized from the surface to the interior and finally transformed into $\gamma-\mathrm{Fe}_{2} \mathrm{O}_{3}$ NPs. This enzymatic-like reaction-triggered oxidation process of $\mathrm{Fe}_{3} \mathrm{O}_{4}$ NPs is analogous to the conventional low-temperature air oxidation of magnetite, in which iron ion migration is the rate-limiting step.

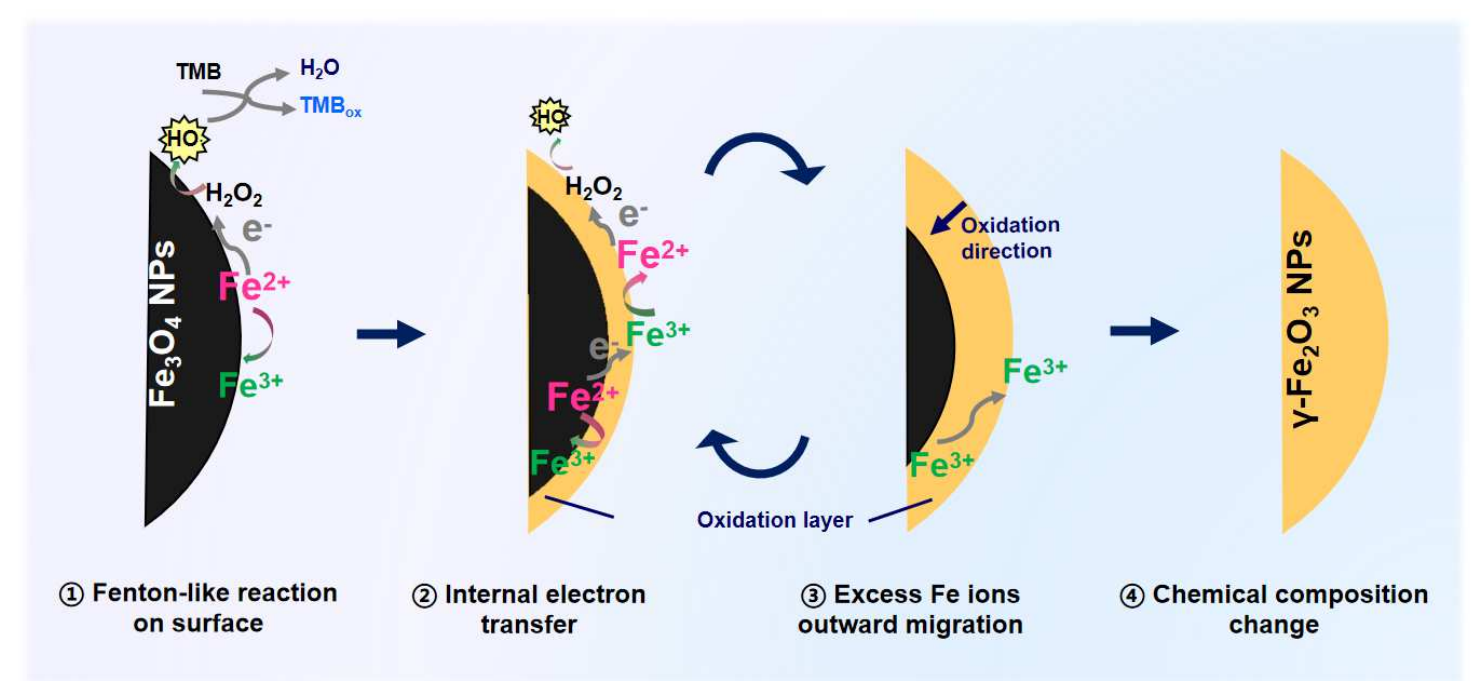

Fig. 3 Schematic diagram of the catalytic mechanism of the POD-like activity for $\mathrm{Fe}_{3} \mathrm{O}_{4} \mathrm{NPs}$.

$\mathrm{LiFePO}_{4} \mathrm{NPs}_{\text {as }}$ an ideal verification model. To test the above mechanism, we found an ideal model material, $\mathrm{LiFePO}_{4}$, which is commonly applied as cathode material for lithium-ion batteries. ${ }^{38-41} \mathrm{LiFePO}_{4}$ undergoes redox reactions along with the lithium insertion/extraction during the charge-discharge process (Equation 5-6) without changing its ordered-olivine structure (Fig. 4a). ${ }^{38}$ We speculate the charging process of $\mathrm{LiFePO}_{4}$ is 
resembling the oxidation process of $\mathrm{Fe}_{3} \mathrm{O}_{4}$, both of which involve the oxidation of $\mathrm{Fe}^{2+}$ and the migration of internal ions, which motivated us to focus on whether $\mathrm{LiFePO}_{4} \mathrm{NPs}$ also have the POD-like catalytic ability.

$$
\begin{aligned}
& \mathrm{LiFePO}_{4}-x \mathrm{Li}^{+}-x e^{-} \rightarrow x \mathrm{FePO}_{4}+(1-x) \mathrm{LiFePO}_{4} \\
& \mathrm{FePO}_{4}+x \mathrm{Li}^{+}+x e^{-} \rightarrow x \mathrm{LiFePO}_{4}+(1-x) \mathrm{FePO}_{4}
\end{aligned}
$$

Rod-like $\mathrm{LiFePO}_{4} \mathrm{NPs}$ with an average length of $321.9 \mathrm{~nm}$ and width of $172.2 \mathrm{~nm}$ (Fig. $4 \mathrm{~b})$ were successfully synthesized using the solvothermal method ${ }^{38}$ and characterized via various methodologies (Supplementary Fig. 10 and Table S1-2). As expected, the POD-like activity of $\mathrm{LiFePO}_{4} \mathrm{NPs}$ was demonstrated with different chromogenic substrates including TMB, ABTS, and OPD (Fig. 4c and Supplementary Fig. 11). Also, they follow pH, temperature as well as NPs concentration dependence and the Michaelis-Menten kinetics (Supplementary Fig. 12-13). The optimal $\mathrm{pH}$ is about 4.0. The ESR spectra show that $\cdot \mathrm{OH}$ was produced from the decomposition of $\mathrm{H}_{2} \mathrm{O}_{2}$ catalyzed by $\mathrm{LiFePO}_{4}$ NPs in a time-dependent manner (Fig. 4d), which is similar to $\mathrm{Fe}_{3} \mathrm{O}_{4}$ NPs. We then compared the POD-like activity of $\mathrm{LiFePO}_{4} \mathrm{NPs}$ and cc- $\mathrm{Fe}_{3} \mathrm{O}_{4} \mathrm{NPs}$ using two oppositely charged substrates (TMB and ABTS) at pH 3.6. The results consistently show that $\mathrm{LiFePO}_{4} \mathrm{NPs}_{\text {s }}$ had higher catalytic ability than cc-Fe $\mathrm{O}_{4}$ NPs (Supplementary Fig. 14), and the $a_{\text {nano }}$ of $\mathrm{LiFePO}_{4} \mathrm{NPs}$ was approximately four times that of $\mathrm{cc}-\mathrm{Fe}_{3} \mathrm{O}_{4} \mathrm{NPs}$, despite their larger particle size (Fig. 4e). These results imply that $\mathrm{LiFePO}_{4}$ NPs may share a similar POD-like catalytic mechanism with $\mathrm{Fe}_{3} \mathrm{O}_{4} \mathrm{NPs}$, differing in that the rapid $\mathrm{Li}^{+}$migration in the lattice of $\mathrm{LiFePO}_{4} \mathrm{NPs}$ confers them a superior POD-like catalytic activity (Fig. 4f). 
a
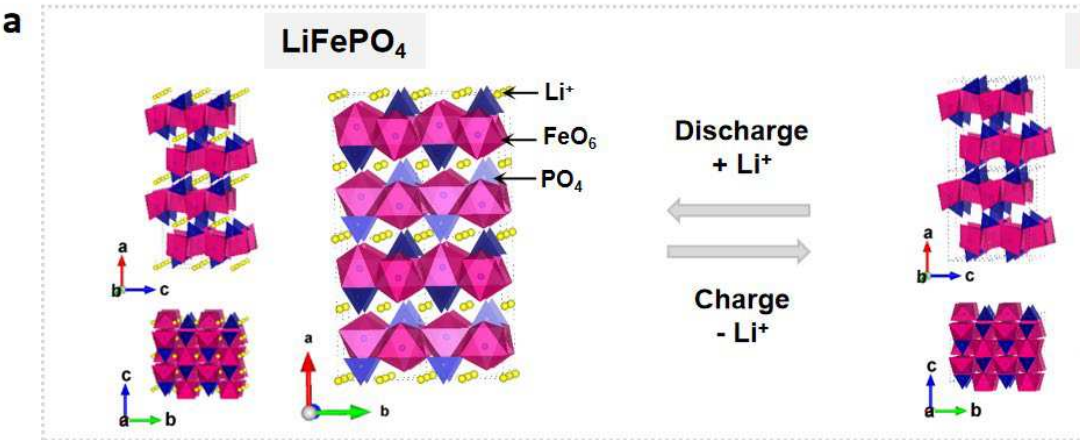

$\mathrm{FePO}_{4}$

b
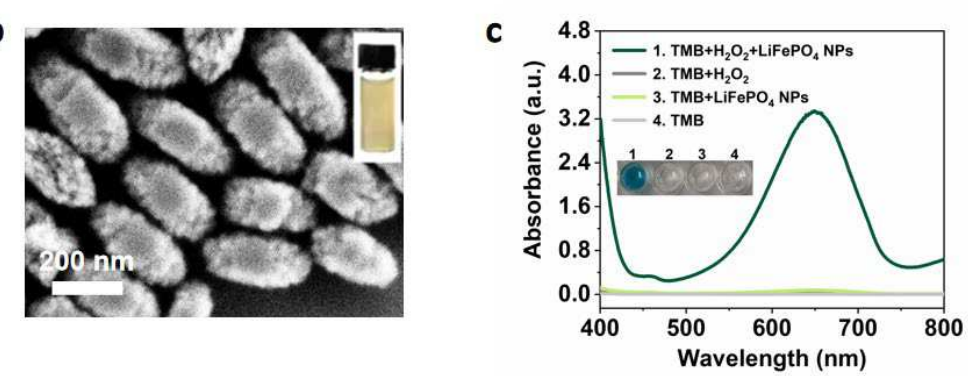

d

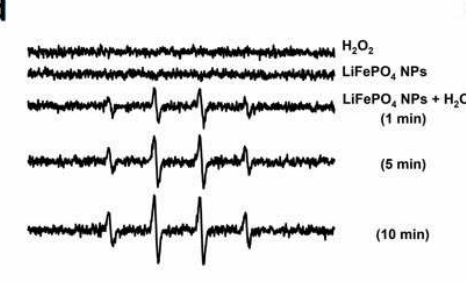

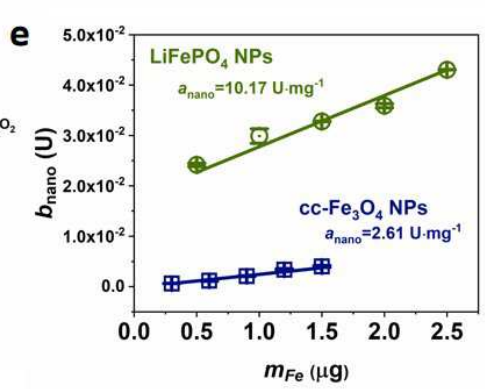

f
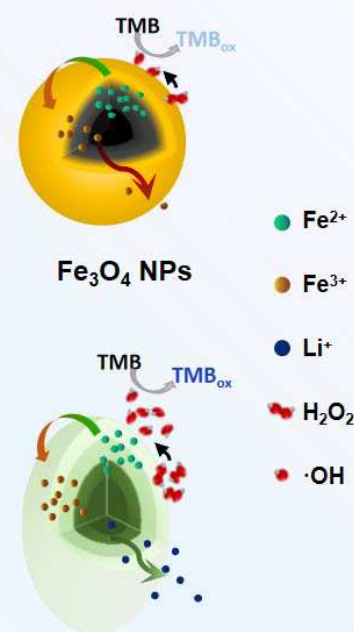

$\mathrm{LiFePO}_{4} \mathrm{NPS}$

Fig. $4 \mathrm{LiFePO}_{4} \mathrm{NPs}_{\text {as }}$ verification materials and their POD-like activity. (a) The crystal structure of $\mathrm{LiFePO}_{4}$ and $\mathrm{FePO}_{4}$ viewed along the $a, b, c$-axis. The olivine structure is maintained during Li-ions insertion and extraction. (b) The SEM image of as-synthesized $\mathrm{LiFePO}_{4} \mathrm{NPs}$. Inset is a photo of $\mathrm{LiFePO}_{4} \mathrm{NPs}$ aqueous solution. (c) The POD-like activity of $\mathrm{LiFePO}_{4} \mathrm{NPs}(6.25 \mathrm{ug}$ $\mathrm{Fe} / \mathrm{mL})$ with TMB $(1.7 \mathrm{mM})$ as colorimetric substrates under the presence of $\mathrm{H}_{2} \mathrm{O}_{2}(0.8 \mathrm{M})$ in 0.2 $\mathrm{M}$ acetate buffer $(\mathrm{pH}=3.6)$. (d) ESR spectra of spin adducts $\mathrm{DMPO} / \cdot \mathrm{OH}$ produced by $\mathrm{LiFePO}_{4}$ NPs $(10 \mathrm{ug} / \mathrm{mL})$ in the presence or absence of $\mathrm{H}_{2} \mathrm{O}_{2}(0.165 \mathrm{M})$ in $0.2 \mathrm{M}$ acetate buffer $(\mathrm{pH}=3.6)$. (e) Comparison of the $a_{\text {nano }}$ of as-synthesized $\mathrm{LiFePO}_{4} \mathrm{NPs}$ and cc-Fe $\mathrm{O}_{3} \mathrm{O}$ NPs. (f) Diagram of the POD-like catalytic reaction process of $\mathrm{LiFePO}_{4} \mathrm{NPs}_{\mathrm{N}}$ and $\mathrm{Fe}_{3} \mathrm{O}_{4} \mathrm{NPs}$.

Phase transformation of $\mathrm{LiFePO}_{4} \mathrm{NPs}_{3}$ caused by catalyzing POD-like reaction. The recycled $\mathrm{LiFePO}_{4} \mathrm{NPs}$ from three cycles of POD-like catalysis were proven to suffer a phase 
transformation to $\mathrm{FePO}_{4}$ via multiple characterization techniques. Specifically, the XPS Fe2p peaks of the recycled $\mathrm{LiFePO}_{4} \mathrm{NPs}$ were shifted toward the higher binding energy (Fig. 5a), indicating the oxidation of $\mathrm{Fe}^{2+}$ within the NPs. In the XRD pattern (Fig. 5b), the residual $\mathrm{LiFePO}_{4}$ phase (marked with "o" in the yellow pattern) in the recycled NPs was negligible, proving that almost all $\mathrm{LiFePO}_{4}$ were delithiated and oxidized into $\mathrm{FePO}_{4}$ (marked with "+”) after cyclic POD-like catalysis. This result was further confirmed by ICP analysis that the Li element content in recycled NPs was almost 0 (Table 1). Moreover, the electrochemical property of the recycled NPs was examined using cyclic voltammetry $(\mathrm{CV})^{43}$ at various scan rates in the voltage range of 0.2 to $0.5 \mathrm{~V}$ (Supplementary Fig. 15). The redox peak currents of the recycled NPs were dramatically reduced due to the absence of $\mathrm{Li}^{+}$in their lattice (Fig. 5c). This phase transformation, as expected, severely impaired the POD-like activity of the recycled $\mathrm{LiFePO}_{4}$ NPs (Fig. 5d), in agreement with the self-depleting characteristic of the $\mathrm{Fe}_{3} \mathrm{O}_{4}$ NPs described above. 
a
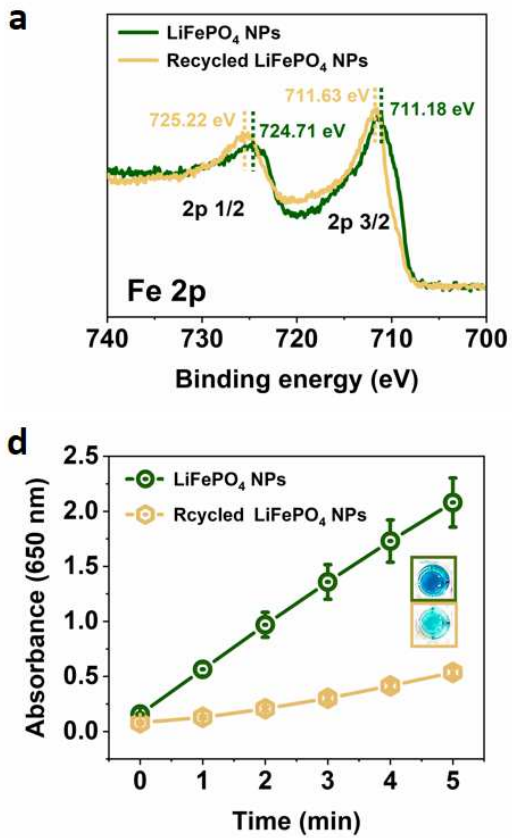

b
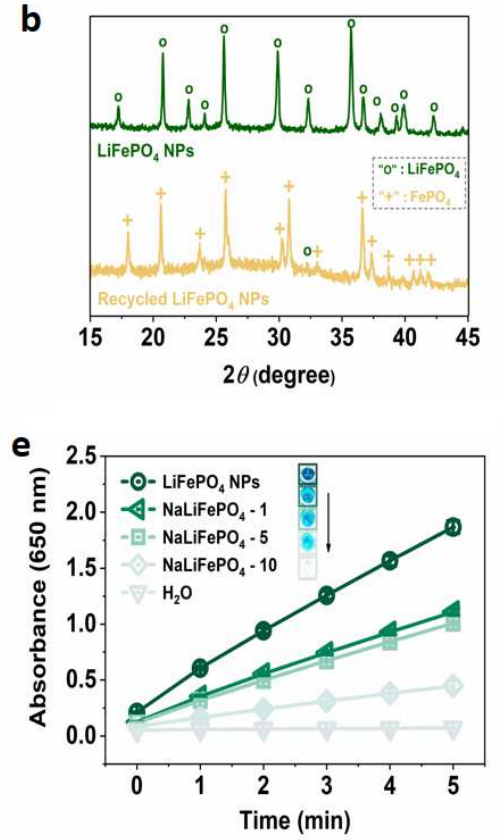

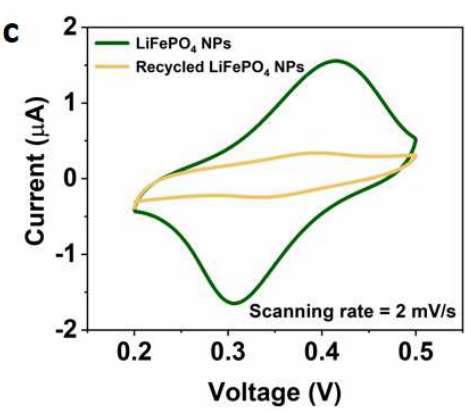

f

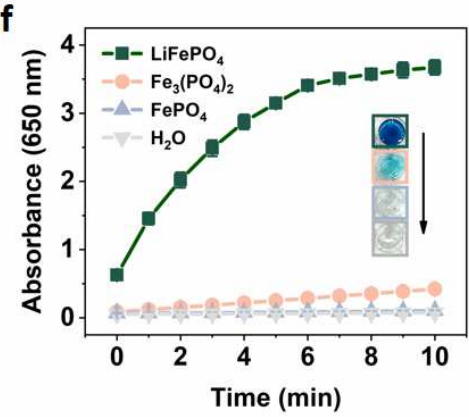

Fig. 5 Catalytic mechanism of the POD-like activity for $\mathrm{LiFePO}_{4}$ NPs. (a) The Fe2p XPS spectra, (b) XRD patterns, (c) CV curves at $2 \mathrm{mV} \cdot \mathrm{s}^{-1}$, and (d) POD-like activities of the control $\mathrm{LiFePO}_{4} \mathrm{NPs}$ and the recycled $\mathrm{LiFePO}_{4} \mathrm{NPs}$ from three cycles of POD-like reaction. The POD-like activity of (e) $\mathrm{NaLiFePO}_{4} \mathrm{NPs}(0.4 \mu \mathrm{g} \mathrm{Fe} / \mathrm{mL})$ with different Na-doping levels, and (f) commercial $\mathrm{LiFePO}_{4}, \mathrm{Fe}_{3}\left(\mathrm{PO}_{4}\right)_{2}$, and $\mathrm{FePO}_{4}(1.25 \mu \mathrm{g} \mathrm{Fe} / \mathrm{mL})$ using TMB $(1.7 \mathrm{mM})$ as substrates in the presence of $\mathrm{H}_{2} \mathrm{O}_{2}(0.8 \mathrm{M})$ at $\mathrm{pH} 3.6$.

Table 1. ICP analysis of the control and recycled $\mathrm{LiFePO}_{4} \mathrm{NPs}$.

\begin{tabular}{ccc}
\hline \multirow{2}{*}{ Element } & \multicolumn{2}{c}{ Concentration $(\boldsymbol{\mu g} / \mathbf{m L})$} \\
\cline { 2 - 3 } $\mathrm{Li}$ & Control $\mathrm{LiFePO}_{4} \mathrm{NPs}$ & Recycled LiFePO 4 \\
NPs \\
$\mathrm{Fe}$ & 15.38 & 0.66 \\
$\mathrm{P}$ & 120.50 & 126.54 \\
Molar ratio of Li: Fe: $\mathrm{P}$ & 71.02 & 63.00 \\
\hline
\end{tabular}


Mobile Li-ions as the limiting factor for $\mathrm{LiFePO}_{4}$ NPs-catalyzed POD-like reaction. In the field of sodium (Na)-ion batteries, the charge transfer resistances and lattice volume change upon $\mathrm{Na}^{+}$migration are larger for $\mathrm{NaFePO}_{4}$ electrodes, compared with their Li equivalents due to the larger ionic radius of $\mathrm{Na}(1.02 \AA)$ than $\mathrm{Li}(0.76 \AA) .{ }^{44}$ Inspired by this, We partially replaced $\mathrm{Li}$ with $\mathrm{Na}$ in the lattice of $\mathrm{LiFePO}_{4} \mathrm{NPs}$ to explore the potential effect of Na-doping on their POD-like activity. Concretely, three $\mathrm{NaLiFePO}_{4}$ NPs with similar physicochemical properties but different Na-doping amounts were successfully synthesized (Supplementary Fig. 16 and Table S3). We then compared their POD-like activities under the same reaction conditions and found that the more $\mathrm{Na}$ doping, the lower the POD-like activity (Fig. 5e), indicating that the large $\mathrm{Na}^{+}$radius hinders the free migration of $\mathrm{Na}^{+}$and $\mathrm{Li}^{+}$in the crystal, thereby impairing the electron transfer rate. We attempted to use $\mathrm{K}$-doped $\mathrm{LiFePO}_{4} \mathrm{NPs}_{\text {s }}$ further proof, however, the large ionic radius of $\mathrm{K}(1.38 \AA$ ) makes it difficult to embed into the electrode materials (Supplementary Fig. 17 and Table S3), which is a common issue in K-ion batteries. ${ }^{45}$

To further prove the decisive role of mobile $\mathrm{Li}^{+}$, we measured the POD-like activity of commercially available $\mathrm{LiFePO}_{4}, \mathrm{Fe}_{3}\left(\mathrm{PO}_{4}\right)_{2}$, and $\mathrm{FePO}_{4}$ materials with similar hydrodynamic dimensions and surface negative potentials (Supplementary Fig. 18). The results show that their POD-like activity follows $\mathrm{LiFePO}_{4}>>\mathrm{Fe}_{3}\left(\mathrm{PO}_{4}\right)_{2}>\mathrm{FePO}_{4}$ (Fig. 5f), directly confirming that the presence of $\mathrm{Fe}^{2+}$ alone in $\mathrm{Fe}_{3}\left(\mathrm{PO}_{4}\right)_{2}$ cannot ensure the superior catalytic performance, but the transportable $\mathrm{Li}^{+}$contributes to the outstanding POD-like activity of $\mathrm{LiFePO}_{4}$. 


\section{Conclusion}

In summary, a detailed mechanism of the POD-like activity of $\mathrm{Fe}_{3} \mathrm{O}_{4}$ nanozymes is elucidated by characterizing the chemical composition and catalytic activity of the $\mathrm{Fe}_{3} \mathrm{O}_{4} \mathrm{NPs}$ recycled from the long-term POD-like catalysis. These studies demonstrate that all $\mathrm{Fe}^{2+}$ in $\mathrm{Fe}_{3} \mathrm{O}_{4}$ nanozymes contribute to their POD-like activity. The $\mathrm{Fe}^{2+}$ inside the particle transfers electrons to the surface, regenerating the surface $\mathrm{Fe}^{2+}$ that is directly involved in the sustained catalytic reaction. This process is accompanied by the outward migration of excess oxidized $\mathrm{Fe}^{3+}$ from the interior of the crystal, which is a rate-limiting step. Analogous to the low-temperature oxidation of magnetite, $\mathrm{Fe}_{3} \mathrm{O}_{4}$ NPs participated in the POD-like reaction are eventually oxidized to $\gamma-\mathrm{Fe}_{2} \mathrm{O}_{3}$ NPs with a reduced POD-like capacity. Furthermore, this mechanism is well-validated on $\mathrm{LiFePO}_{4} \mathrm{NPs}$. This work reveals the depletable characteristic of $\mathrm{Fe}_{3} \mathrm{O}_{4}$ nanozymes that differ from natural enzymes and highlights the potential contribution of internal metal atoms in nanozymes-catalyzed reactions. Meanwhile, these findings bring new thoughts for the mechanistic study and rational design of nanozymes. 


\section{Materials and Methods}

Chemicals. Ferrous sulfate heptahydrate $\left(\mathrm{FeSO}_{4} \cdot 7 \mathrm{H}_{2} \mathrm{O}\right)$, iron (III) chloride hexahydrate $\left(\mathrm{FeCl}_{3} \cdot 6 \mathrm{H}_{2} \mathrm{O}\right.$ ), dimethyl sulfoxide (DMSO), 3, 3', 5, 5'-tetramethylbenzidine (TMB, $\geq 99 \%$ ), 2 , 2'-azino-bis(3-ethylbenzothiazoline-6-sulfonic acid) (ABTS, 98\%), o-Phenylenediamine (OPD, 98\%), ferric oxide $\left(\mathrm{Fe}_{2} \mathrm{O}_{3}\right)$, iron acetylacetonate [Fe(acac) $)_{3}$, oleic acid (OA), dibenzyl ether, lithium hydroxide $\left(\mathrm{LiOH} \cdot \mathrm{H}_{2} \mathrm{O}\right)$, ferric phosphate $\left(\mathrm{FePO}_{4}\right)$, rhodamine $\mathrm{B}(\mathrm{RhB})$, terephthalic acid (TA), sodium carbonate $\left(\mathrm{Na}_{2} \mathrm{CO}_{3}\right)$, and sodium acetate $\left(\mathrm{CH}_{3} \mathrm{COONa}\right)$ were purchased from Aladdin (Shanghai, China). Tetramethylammonium hydroxide (TMAOH) and 5,5-dimethyl-1-pyrroline N-oxide (DMPO) were purchased from Sigma Aldrich. Hydrochloric acid $(\mathrm{HCl}, 36.0 \%-38.0 \%)$, nitric acid $\left(\mathrm{HNO}_{3}\right)$, phosphoric acid $\left(\mathrm{H}_{3} \mathrm{PO}_{4}, 85 \% \mathrm{wt}\right)$, acetic acid $\left(\mathrm{CH}_{3} \mathrm{COOH}\right)$, hydrogen peroxide $\left(\mathrm{H}_{2} \mathrm{O}_{2}, 30 \%\right)$, ethyl alcohol, ethylene glycol (EG), and potassium hydroxide $(\mathrm{KOH})$ were purchased from Sinopharm Chemical Reagent Co., Ltd. Ferrous phosphate $\left[\mathrm{Fe}_{3}\left(\mathrm{PO}_{4}\right)_{2}\right]$ was purchased from Shanghai Maclin Biochemical Technology Co., Ltd. Lithium iron phosphate $\left(\mathrm{LiFePO}_{4}\right)$ was purchased from Shanghai Xushuo Biological Technology Co., Ltd. All chemicals were used as received without further purification. Deionized water was used throughout the experiments.

Characterization. The particle size and morphology were observed by scanning electron microscopy (SEM, Ultra Plus, Carl Zeiss, Germany). Transmission electron microscopy, selective area electron diffraction (SAED), and high-resolution TEM (HRTEM) were taken using transmission electron microscopy (TEM, JEOL JEM-2100F, Japan). The phase and crystalline structure were explored by X-ray diffraction analyzer (XRD, Brucker D8 Advance, 
Germany) using $\mathrm{Cu} \mathrm{Ka}$ radiation. The element composition, chemical structures, and properties of nanoparticles were analyzed by SEM energy dispersive spectroscopy (EDS), ICP-OES (Agilent ICPOES730), Fourier transform infrared spectroscopy (FTIR, Nicolet IS 10, Thermo, USA), Raman spectrometer (Renishaw Invia, UK) and X-ray photoelectron spectroscopy (XPS, Thermo ESCALAB 250Xi, USA). The chemical speciation of Fe in IONPs was determined by X-ray absorption near-edge fine structure (NEXAFS) at the beamline of 08U1A in the Shanghai Synchrotron Radiation Facility (SSRF), Shanghai, China. The NEXAFS spectra of the references including $\mathrm{FeSO}_{4}$ and $\mathrm{Fe}_{2} \mathrm{O}_{3}$ were also measured. Hydrodynamic diameters and Zeta potential of particles were measured by the dynamic light scattering (DLS, Nano-ZS90, Malvern, England). The UV-Vis-NIR absorption spectra were measured using UV3600 (Shimadzu, Japan) and a matched quartz cuvette with $1 \mathrm{~cm}$ optical path. Cyclic voltammetry (CV) of $\mathrm{LiFePO}_{4}$ was measured on Electrochemical Workstation (CHI760e). The production of $\cdot \mathrm{OH}$ was detected by the electron spin resonance spectrometer (ESR, Bruker EMXplus, Germany) at ambient temperature. Error bars shown in this paper represent the standard error derived from three repeated measurements.

\section{Synthesis of $\mathrm{Fe}_{3} \mathrm{O}_{4} \mathrm{NPs}, \gamma-\mathrm{Fe}_{2} \mathrm{O}_{3} \mathrm{NPs}$, and $\alpha-\mathrm{Fe}_{2} \mathrm{O}_{3} \mathrm{NPs}$ by chemical coprecipitation}

method. The naked magnetite nanoparticles were synthesized by a modified chemical coprecipitation method, namely, cc- $\mathrm{Fe}_{3} \mathrm{O}_{4} \mathrm{NPs} .{ }^{18}$ In brief, $2.7025 \mathrm{~g}$ of $\mathrm{FeCl}_{3} \cdot 6 \mathrm{H}_{2} \mathrm{O}$ and $1.39 \mathrm{~g}$ $\mathrm{FeSO}_{4} \cdot 7 \mathrm{H}_{2} \mathrm{O}$ were added to a $100 \mathrm{~mL}$ three-necked flask with $10 \mathrm{~mL}$ of $2 \mathrm{M} \mathrm{HCl}$ reaction solvent. The mixture was stirred at $400 \mathrm{rpm}$ for $10 \mathrm{~min}$ under a nitrogen gas $\left(\mathrm{N}_{2}\right)$ atmosphere. Then, $62.5 \mathrm{~mL}$ of $12.5 \% \mathrm{TMAOH}$ was quickly poured into the above flask and stirred at 700 
rpm for $1 \mathrm{~h}$ at room temperature. $\mathrm{N}_{2}$ was introduced throughout the experiment to remove $\mathrm{O}_{2}$ from the reaction system. The reaction solution was transferred to a beaker and washed with deoxygenated water three times by magnetic decantation to remove the residual reagents. Part of obtained precipitate was dispersed into deionized water with a $\mathrm{pH}$ of 3 to obtain the cc- $\mathrm{Fe}_{3} \mathrm{O}_{4} \mathrm{NPs}$ suspensions, which were stored at $4{ }^{\circ} \mathrm{C}$ for subsequent experiments.

The remaining cc- $\mathrm{Fe}_{3} \mathrm{O}_{4}$ NPs precipitates were dried into black $\mathrm{Fe}_{3} \mathrm{O}_{4} \mathrm{NPs}$ powder under vacuum, and then calcined at $200{ }^{\circ} \mathrm{C}$ and $650{ }^{\circ} \mathrm{C}$ for $2 \mathrm{~h}$ to obtain $\gamma-\mathrm{Fe}_{2} \mathrm{O}_{3} \mathrm{NPs}$ and $\alpha-\mathrm{Fe}_{2} \mathrm{O}_{3}$ NPs powder, respectively. ${ }^{25}$ Finally, these three powders were dissolved in a $\mathrm{pH}$ of 3 aqueous solutions by ultrasound and stored at $4{ }^{\circ} \mathrm{C}$ for subsequent experiments.

Synthesis of $\mathrm{Fe}_{3} \mathrm{O}_{4} \mathrm{NPs}$ by thermal decomposition method. Firstly, the OA-coated $\mathrm{Fe}_{3} \mathrm{O}_{4}$ NPs were synthesized according to the thermal decomposition method we previously reported (denoted as TD-Fe $\mathrm{O}_{4} @ \mathrm{OA} \mathrm{NPs}$. ${ }^{36}$ Then, 4 mL of TD-Fe $\mathrm{O}_{4} @ \mathrm{OA}$ NPs $(1.627 \mathrm{mg} \mathrm{Fe} / \mathrm{mL}$ ) was used to remove the solvent chloroform by rotary evaporation. Next, The remaining precipitates were ultrasonically dissolved in $15 \mathrm{~mL}$ of deionized water containing $0.5 \%$ TMAOH under vigorous stirring. ${ }^{46}$ Then, the reaction system was transferred to $60 \mathrm{~mL}$ of the separatory funnel, and $45 \mathrm{~mL}$ of chloroform was added. The mixture was thoroughly mixed. After standing for $15 \mathrm{~min}$, the underlying oil phase liquid was discarded. This extraction procedure was repeated three times to fully remove the free OA that was replaced from the surface of particles by TMAOH. Finally, the obtained $\mathrm{Fe}_{3} \mathrm{O}_{4}$ NPs aqueous solution (denoted as $\mathrm{TD}-\mathrm{Fe}_{3} \mathrm{O}_{4} \mathrm{NPs}$ ) was filtered through a $0.22 \mu \mathrm{m}$ filter and stored at $4{ }^{\circ} \mathrm{C}$ for subsequent experiments. 
Synthesis of $\mathrm{LiFePO}_{4} \mathrm{NPs}$ and $\mathrm{Na}$ or $\mathrm{K}$-doped $\mathrm{LiFePO}_{4} \mathrm{NPs} \mathrm{LiFePO}_{4} \mathrm{NPs}$ were successfully synthesized by glycol-based solvothermal method as previously reported. ${ }^{42}$ In a typical route, $0.27 \mathrm{~mL} \mathrm{H} \mathrm{PO}_{4}(85 \% \mathrm{wt})$ was dropped into $9 \mathrm{~mL}$ of ethylene glycol (EG) containing $0.365 \mathrm{~g}$ of $\mathrm{LiOH} \cdot \mathrm{H}_{2} \mathrm{O}$. The mixture was stirred thoroughly until the neutralization reaction was complete, showing a milk-white suspension. Then $9 \mathrm{~mL}$ of EG dissolved $0.890 \mathrm{~g}$ $\mathrm{FeSO}_{4} \cdot 7 \mathrm{H}_{2} \mathrm{O}$ was added into the suspension under vigorous stirring. The mixtures slowly turned grayish-green. After stirring for $30 \mathrm{~min}$, the reaction solution was transferred into a sealed hydrothermal reactor, heated at $180{ }^{\circ} \mathrm{C}$ for $10 \mathrm{~h}$. At the end of the reaction, the final products were cooled down to room temperature and washed with deionized water three times.

For $\mathrm{Na}$ or $\mathrm{K}$-doped $\mathrm{LiFePO}_{4} \mathrm{NPs}$, the Li element content (8.69 mmol) of 1\%, 5\%, and $10 \%$ in the above method was replaced with $\mathrm{Na}$ element in $\mathrm{Na}_{2} \mathrm{CO}_{3}$ or $\mathrm{K}$ element in $\mathrm{KOH}$. The rest of the synthesis steps remained unchanged. Briefly, for Na-doped $\mathrm{LiFePO}_{4} \mathrm{NPs}, 0.365 \mathrm{~g}$ of $\mathrm{LiOH} \cdot \mathrm{H}_{2} \mathrm{O}$ was replaced with $4.6 \mathrm{mg}$ of $\mathrm{Na}_{2} \mathrm{CO}_{3}$ and $0.361 \mathrm{~g}$ of $\mathrm{LiOH} \cdot \mathrm{H}_{2} \mathrm{O}$ (denoted as $\mathrm{NaLiFePO} 4-1$ ), $23.0 \mathrm{mg}$ of $\mathrm{Na}_{2} \mathrm{CO}_{3}$ and $0.346 \mathrm{~g}$ of $\mathrm{LiOH} \cdot \mathrm{H}_{2} \mathrm{O}$ (denoted as $\mathrm{NaLiFePO}_{4}-5$ ), and $46.1 \mathrm{mg}$ of $\mathrm{Na}_{2} \mathrm{CO}_{3}$ and $0.328 \mathrm{~g}$ of $\mathrm{LiOH} \cdot \mathrm{H}_{2} \mathrm{O}$ (denoted as $\mathrm{NaLiFePO}_{4}-10$ ), respectively. For K-doped $\mathrm{LiFePO}_{4} \mathrm{NPs}, 0.365 \mathrm{~g}$ of $\mathrm{LiOH} \cdot \mathrm{H}_{2} \mathrm{O}$ was replaced with $4.9 \mathrm{mg}$ of $\mathrm{KOH}$ and $0.361 \mathrm{~g}$ of $\mathrm{LiOH} \cdot \mathrm{H}_{2} \mathrm{O}$ (denoted as $\mathrm{KLiFePO}_{4}-1$ ), $24.3 \mathrm{mg}$ of $\mathrm{KOH}$ and $0.346 \mathrm{~g}$ of $\mathrm{LiOH} \cdot \mathrm{H}_{2} \mathrm{O}$ (denoted as $\mathrm{KLiFePO}_{4}-5$ ), and $48.7 \mathrm{mg}$ of $\mathrm{KOH}$ and $0.328 \mathrm{~g}$ of $\mathrm{LiOH} \cdot \mathrm{H}_{2} \mathrm{O}$ (denoted as $\mathrm{KLiFePO}_{4}-10$ ), respectively. 
The POD-like activity of NPs. The POD-like activity of NPs was measured by different colorimetric substrates, including TMB, ABTS, and $\mathrm{OPD}$, in the presence of $\mathrm{H}_{2} \mathrm{O}_{2}$ under different reaction conditions. The absorbance of the colored oxidation products at the corresponding wavelength $\left(\mathrm{TMB}_{\text {ox }}: 650 \mathrm{~nm}\right.$; ABTS $_{\text {ox }}$ : $415 \mathrm{~nm}$; OPD $\left._{\text {ox }}: 492 \mathrm{~nm}\right)$ was monitored by UV-Vis spectroscopy. The effects of $\mathrm{pH}(2.5-11)$, temperature $\left(10-65^{\circ} \mathrm{C}\right)$ and $\mathrm{LiFePO}_{4} \mathrm{NPs}_{\text {concentration }}(0-6.25 \mu \mathrm{g} \mathrm{Fe} / \mathrm{mL})$ on POD-like activity were also studied.

Measurement of the specific activity $\left(\boldsymbol{a}_{\text {nano }}\right)$ of NPs. The POD-like specific activity of NPs synthesized in this work was determined according to the modified method specified in the national standard of China (GB/T 37966-2019). ${ }^{26}$ The following provided the general procedures: a. Monitor the temperature inside the quartz cuvette and incubate all reagents and samples to $25^{\circ} \mathrm{C}$; b. Add $2.000 \mathrm{~mL}$ of $0.2 \mathrm{M}$ acetate buffer solution $(\mathrm{pH}=3.6)$ to a reaction container; c. Add $0.100 \mathrm{~mL}$ of different concentrations of NPs and $0.100 \mathrm{~mL}$ of $10 \mathrm{mg} / \mathrm{mL}$ of TMB in order, mix completely and incubate for $60 \mathrm{~s}$ at $25^{\circ} \mathrm{C}$; d. Add $0.100 \mathrm{~mL}$ of $30 \% \mathrm{H}_{2} \mathrm{O}_{2}$ and mix completely; e. Immediately transfer the appropriate amount of reaction solution to the cuvette and monitor the changes of absorbance at $650 \mathrm{~nm}$ within the specified times. The initial change rate of absorbance $\left(\mathrm{min}^{-1}\right)$ is obtained from the slope of the early phase of time course; f. Measurement of reagent blank rate 1 and reagent blank rate 2: $30 \% \mathrm{H}_{2} \mathrm{O}_{2}$ and NPs are respectively replaced by deionized water. The measurement procedure is as described in Step a-e above; g. After deducting the reagent blank rate 1 and 2, the POD-like catalytic activity units ( $b_{\text {nano }}$ ) of NPs can be calculated according to Equation (7):

$$
b_{\text {nano }}=\frac{V \times(\Delta A / \Delta t)}{\varepsilon \times l}
$$


where $b_{\text {nano }}$ is the POD-like catalytic activity units of NPs $(\mathrm{U}) ; V$ is the total volume of reaction solution $(\mu \mathrm{L}) ; \Delta A / \Delta t$ is the slope of the initial liner portion of absorbance changing over time after correcting with reagent blank rate 1 and $2\left(\mathrm{~min}^{-1}\right) ; \varepsilon$ is the molar absorption coefficient of TMB derivative $\left(39000 \mathrm{~mol}^{-1} \cdot \mathrm{L} \cdot \mathrm{cm}^{-1}\right) ; l$ is the optical path of the cuvette $(\mathrm{cm})$.

The specific activity of NPs $\left(a_{\text {nano }}\right)$ can be calculated according to Equation (8):

$$
a_{\text {nano }}=\frac{\Delta b_{\text {nano }}}{\Delta m_{F e}}
$$

where $a_{\text {nano }}$ is the specific activity of NPs $\left(\mathrm{U} \cdot \mathrm{mg}^{-1}\right) ; m_{\mathrm{Fe}}$ is the total Fe element mass contained in added NPs (mg); $\frac{\Delta b_{\text {nano }}}{\Delta m_{F e}}$ is the slope of the curve plotting the $b_{\text {nano }}$ against different masses of NPs $\left(m_{\mathrm{Fe}}\right)$.

ESR measurement. The production of $\cdot \mathrm{OH}$ was detected by adding $10 \mu \mathrm{g} \mathrm{Fe} / \mathrm{mL}$ of cc- $-\mathrm{Fe}_{3} \mathrm{O}_{4}$ NPs or $\mathrm{LiFePO}_{4} \mathrm{NPs}$ and $30 \mathrm{mM}$ of DMPO into $300 \mu \mathrm{L}$ of acetate buffer $(\mathrm{pH}=3.6)$ with or without $0.5 \% \mathrm{H}_{2} \mathrm{O}_{2}$. The signal of the spin adduct $(\mathrm{DMPO} / \cdot \mathrm{OH})$ was recorded at ambient temperature by ESR spectrum at the $1^{\text {st }}, 5^{\text {th }}$, and $10^{\text {th }}$ min after all reagents were mixed. The experimental parameters were as follows: $1 \mathrm{G}$ modulation amplitude, $100 \mathrm{kHz}$ modulation frequency, $6.325 \mathrm{~mW}$ microwave power, $9.829 \mathrm{GHz}$ resonance frequency.

Cyclic POD-like catalysis of NPs. For IONPs, $0.1 \mathrm{~g}$ of $\mathrm{Fe}_{3} \mathrm{O}_{4} \mathrm{NPs}$ or $\gamma-\mathrm{Fe}_{2} \mathrm{O}_{3}$ NPs powder was added to a $400 \mathrm{~mL}$ of acetate buffer (pH 3.6) containing $20 \mathrm{~mL}$ TMB $(10 \mathrm{mg} / \mathrm{mL})$ and 40 $\mathrm{mL}$ of $30 \% \mathrm{H}_{2} \mathrm{O}_{2}$. This catalytic reaction system lasted for one day $(20 \mathrm{~h})$ at $25^{\circ} \mathrm{C}$. After catalysis, $\mathrm{Fe}_{3} \mathrm{O}_{4}$ NPs or $\gamma-\mathrm{Fe}_{2} \mathrm{O}_{3}$ NPs in reaction solution were recycled by magnetic separation, and then ultrasonic washed with deionized water several times. The recycled NPs 
were re-added into a new reaction system mentioned above to catalyze a new round of POD-like reactions. Totally, 5 rounds (or days) of catalysis were carried out, and each round lasted for $20 \mathrm{~h}$ at $25^{\circ} \mathrm{C}$. The $\mathrm{Fe}_{3} \mathrm{O}_{4} \mathrm{NPs}$ recycled on days $0,1,3$, and 5 were taken for further characterization.

For $\mathrm{LiFePO}_{4} \mathrm{NPs}, 1 \mathrm{~mL}$ of $\mathrm{LiFePO}_{4} \mathrm{NPs}(8.4 \mathrm{mg} \mathrm{Fe} / \mathrm{mL})$ was added to a $20 \mathrm{~mL}$ of acetate buffer (pH 3.6) containing $1 \mathrm{~mL}$ TMB $(10 \mathrm{mg} / \mathrm{mL})$ and $2 \mathrm{~mL}$ of $30 \% \mathrm{H}_{2} \mathrm{O}_{2}$. This catalytic reaction system lasted for one hour at $25{ }^{\circ} \mathrm{C}$. After catalysis, $\mathrm{LiFePO}_{4} \mathrm{NPs}$ in the reaction solution were recycled by centrifugation, and then ultrasonic washed with deionized water several times. The recycled $\mathrm{LiFePO}_{4} \mathrm{NPs}$ were re-added into a new reaction system mentioned above to catalyze a new round of POD-like reactions. Totally, 3 rounds of catalysis were carried out, and each round lasted for $1 \mathrm{~h}$ at $25^{\circ} \mathrm{C}$. The $\mathrm{LiFePO}_{4} \mathrm{NPs}$ recycled from the 0 and 3 rounds were taken for further characterization.

Aerated oxidation of $\mathrm{Fe}_{3} \mathrm{O}_{4}$ NPs. $170 \mathrm{~mL}$ of the as-synthesized cc- $\mathrm{Fe}_{3} \mathrm{O}_{4}$ NPs suspensions ( $3.57 \mathrm{mg} \mathrm{Fe} / \mathrm{mL}$ ) were transferred into a $250 \mathrm{~mL}$ three-necked flask and heated from room temperature to $120^{\circ} \mathrm{C}$. Air was pumped into the suspension at a constant rate $(9 \mathrm{~L} / \mathrm{min})$ for 12 $\mathrm{h}$ under stirring $(350 \mathrm{rpm})$. Condensation reflux was kept throughout the aeration oxidation. Samples oxidized at $0,0.5,1,3,5,810$, and $12 \mathrm{~h}$ were used for subsequent characterization.

As for TD- $\mathrm{Fe}_{3} \mathrm{O}_{4} \mathrm{NPs}$, the only difference was that $30 \mathrm{~mL}$ of $\mathrm{TD}-\mathrm{Fe}_{3} \mathrm{O}_{4} \mathrm{NPs}(0.45 \mathrm{mg}$ $\mathrm{Fe} / \mathrm{mL}$ ) were transferred into a $100 \mathrm{~mL}$ three-necked flask. Other steps were consistent with the aeration oxidation of $\mathrm{cc}-\mathrm{Fe}_{3} \mathrm{O}_{4} \mathrm{NPs}$. 
Electrochemical performance of $\mathrm{LiFePO}_{4}$ NPs. Cyclic voltammetry (CV) was used to evaluate the electrochemical performance of $\mathrm{LiFePO}_{4} \mathrm{NPs}$ and recycled $\mathrm{LiFePO}_{4} \mathrm{NPs}$ in a three-electrode cell. ${ }^{43}$ Saturated calomel was used as the reference electrode and platinum wire as the counter electrode. NPs were mixed with $0.5 \%$ Nafion solution in a $1: 9$ volume ratio and dropped into the polished glassy carbon electrode, which was dried and used as the working electrode. The electrolyte solution was $0.2 \mathrm{M}$ acetate buffer $(\mathrm{pH}=3.6)$. CV was recorded between 0.2 and $0.5 \mathrm{~V}$ at voltage scan rate $(\mathrm{v})$ ranging from 0.2 to $2 \mathrm{mV} \cdot \mathrm{s}^{-1}$.

\section{Data availability}

The data supporting the findings of this study are available within the article and its

Supplementary Information files. All other relevant source data are available from

the corresponding authors upon reasonable request.

\section{References}

1. Wei, H. et al. Nanozymes: a clear definition with fuzzy edges. Nano Today. 40, 101269 (2021).

2. Liu, Q., Zhang, A., Wang, R., Zhang, Q. \& Cui, D. A review on metal- and metal oxide-based nanozymes: properties, mechanisms, and applications. Nano-micro letters. 13, 1-53 (2021).

3. Zhang, R., Yan, X. \& Fan, K. Nanozymes inspired by natural enzymes. Accounts of Materials Research. 2, 534-547 (2021).

4. Tang, G., He, J., Liu, J., Yan, X. \& Fan, K. Nanozyme for tumor therapy: surface modification matters. Exploration. 1, 75-89 (2021).

5. $\mathrm{Wu}, \mathrm{Y}$. et al. Defect engineering in nanozymes. Mater. Today, (2021).

6. Kang, T., Kim, Y. G., Kim, D. \& Hyeon, T. Inorganic nanoparticles with enzyme-mimetic activities for biomedical applications. Coordin. Chem. Rev. 403, 213092 (2020).

7. Wang, Z., Zhang, R., Yan, X. \& Fan, K. Structure and activity of nanozymes: inspirations for $d e$ novo design of nanozymes. Mater. Today. 41, 81-119 (2020).

8. Xiang, H., Feng, W. \& Chen, Y. Advanced materials-single-atom catalysts in catalytic biomedicine. Adv. Mater. 32, 1905994 (2020).

9. Liang, M. \& Yan, X. Nanozymes: from new concepts, mechanisms, and standards to applications. Accounts Chem. Res. 52, 2190-2200 (2019). 
10. Gao, L. et al. Intrinsic peroxidase-like activity of ferromagnetic nanoparticles. Nat. Nanotechnol. 2 , 577-583 (2007).

11. Cheng, L. et al. Unveiling the actual catalytic sites in nanozyme-catalyzed oxidation of o-Phenylenediamine. Small. 17, 2104083 (2021).

12. Chen, J. et al. Glucose-oxidase like catalytic mechanism of noble metal nanozymes. Nat. Commun. 12, 3375 (2021).

13. Zhang, R. et al. Unveiling the active sites on ferrihydrite with apparent catalase-like activity for potentiating radiotherapy. Nano Today. 41, 101317 (2021).

14. Shen, X., Wang, Z., Gao, X. \& Zhao, Y. Density functional theory-based method to predict the activities of nanomaterials as peroxidase mimics. ACS Catal. 10, 12657-12665 (2020).

15. Guo, S. \& Guo, L. Unraveling the multi-enzyme-like activities of iron oxide nanozyme via a first-principles microkinetic study. The Journal of Physical Chemistry C. 123, 30318-30334 (2019).

16. Raineri, M. et al. Effects of biological buffer solutions on the peroxidase-like catalytic activity of $\mathrm{Fe}_{3} \mathrm{O}_{4}$ nanoparticles. Nanoscale. 11, 18393-18406 (2019).

17. Moreno Maldonado, A. C. et al. Free-radical formation by the peroxidase-like catalytic activity of $\mathrm{MFe}_{2} \mathrm{O}_{4}(\mathrm{M}=\mathrm{Fe}, \mathrm{Ni}$, and $\mathrm{Mn})$ nanoparticles. The Journal of Physical Chemistry C. 123, 20617-20627 (2019).

18. Chen, Z. et al. Dual enzyme-like activities of iron oxide nanoparticles and their implication for diminishing cytotoxicity. ACS Nano. 6, 4001-4012 (2012).

19. Wang, N. et al. Sono-assisted preparation of highly-efficient peroxidase-like $\mathrm{Fe}_{3} \mathrm{O}_{4}$ magnetic nanoparticles for catalytic removal of organic pollutants with $\mathrm{H}_{2} \mathrm{O}_{2}$. Ultrason. Sonochem. 17, 526-533 (2010).

20. Dong, H., Fan, Y., Zhang, W., Gu, N. \& Zhang, Y. Catalytic mechanisms of nanozymes and their applications in biomedicine. Bioconjugate Chem. 30, 1273-1296 (2019).

21. Wu, H. et al. Enhanced tumor synergistic therapy by injectable magnetic hydrogel mediated generation of hyperthermia and highly toxic reactive oxygen species. ACS Nano. 13, 14013-14023 (2019).

22. Fan, K. et al. Optimization of $\mathrm{Fe}_{3} \mathrm{O}_{4}$ nanozyme activity via single amino acid modification mimicking an enzyme active site. Chem. Commun. 53, 424-427 (2017).

23. Voinov, M. A., Pagán, J. O. S., Morrison, E., Smirnova, T. I. \& Smirnov, A. I. Surface-mediated production of hydroxyl radicals as a mechanism of iron oxide nanoparticle biotoxicity. J. Am. Chem. Soc. 133, 35-41 (2011).

24. Zandieh, M. \& Liu, J. Nanozyme catalytic turnover and self-limited reactions. ACS Nano. 15, 15645-15655 (2021).

25. Colombo, U., Gazzarrini, F., Lanzavecchia, G. \& Sironi, G. Magnetite oxidation: a proposed mechanism. Science. 147, 1033 (1965).

26. GB/T 37966-2019, Nanotechnologies - Measurement Method for Peroxidase-like Activity of Iron Oxide Nanoparticles, National Technical Committee on Nanotecnology of Standardization Administration, Beijing, China, 2019.

27. Jiang, B. et al. Standardized Assays for Determining the Catalytic Activity and Kinetics of Peroxidase-like Nanozymes. Nat. Protoc. 13, 1506-1520 (2018).

28. Zhang, L. et al. Facile synthesis of iron oxides/reduced graphene oxide composites: application for electromagnetic wave absorption at high temperature. Sci. Rep.-UK. 5, (2015).

29. Gao, J. et al. One-step solvothermal synthesis of highly water-soluble, negatively charged 
superparamagnetic $\mathrm{Fe}_{3} \mathrm{O}_{4}$ colloidal nanocrystal clusters. Nanoscale. 5, 7026 (2013).

30. Sun, S. et al. Monodisperse $\mathrm{MFe}_{2} \mathrm{O}_{4}$ (M = Fe, Co, Mn) nanoparticles. J. Am. Chem. Soc. 126, 273-279 (2004).

31. Park, J. et al. One-nanometer-scale size-controlled synthesis of monodisperse magnetic iron oxide nanoparticles. Angew. Chem. 117, 2932-2937 (2005).

32. Park, J. et al. Ultra-large-scale syntheses of monodisperse nanocrystals. Nat. Mater. 3, 891-895 (2004).

33. Sun, Y., Ma, M., Zhang, Y. \& Gu, N. Synthesis of nanometer-size maghemite particles from magnetite. Colloids Surf., A. 245, 15-19 (2004).

34. Sidhu, P. S., Gilkes, R. J. \& Posner, A. M. Mechanism of the low temperature oxidation of synthetic magnetites. J. Inorg. Nucl. Chem. 39, 1953-1958 (1977).

35. Colombo, U., Fagherazzi, G., Gazzarrini, F., Lanzavecchia, G. \& Sironi, G. Mechanism in the first stage of oxidation of magnetites. Nature. 202, 175-176 (1964).

36. Kong, F. et al. $\mathrm{Fe}_{3} \mathrm{O}_{4} @ \mathrm{Pt}$ nanozymes combining with $\mathrm{CXCR}_{4}$ antagonists to synergistically treat acute myeloid leukemia. Nano Today. 37, 101106 (2021).

37. Tang, J., Myers, M., Bosnick, K. A. \& Brus, L. E. Magnetite $\mathrm{Fe}_{3} \mathrm{O}_{4}$ nanocrystals: spectroscopic observation of aqueous oxidation kinetics. The Journal of Physical Chemistry B. 107, 7501-7506 (2003)

38. Yuan, L. et al. Development and challenges of $\mathrm{LiFePO}_{4}$ cathode material for lithium-ion batteries. Energy Environ. Sci. 4, 269-284 (2011).

39. Wang, J. \& Sun, X. Understanding and recent development of carbon coating on $\mathrm{LiFePO}_{4}$ cathode materials for lithium-ion batteries. Energ. Environ. Sci. 5, 5163-5185 (2012).

40. Wang, J. \& Sun, X. Olivine $\mathrm{LiFePO}_{4}$ : the remaining challenges for future energy storage. Energ. Environ. Sci. 8, 111-1138 (2015).

41. Bai, P., Cogswell, D. A. \& Bazant, M. Z. Suppression of phase separation in $\mathrm{LiFePO}_{4}$ nanoparticles during battery discharge. Nano Lett. 11, 4890-4896 (2011).

42. Wang, L. et al. Crystal orientation tuning of $\mathrm{LiFePO}_{4}$ nanoplates for high rate lithium battery cathode materials. Nano Lett. 12, 5632-5636 (2012).

43. Tang, K., Yu, X., Sun, J., Li, H. \& Huang, X. Kinetic analysis on $\mathrm{LiFePO}_{4}$ thin films by CV, GITT, and EIS. Electrochim. Acta. 56, 4869-4875 (2011).

44. Zhu, Y., Xu, Y., Liu, Y., Luo, C. \& Wang, C. Comparison of electrochemical performances of olivine $\mathrm{NaFePO}_{4}$ in sodium-ion batteries and olivine $\mathrm{LiFePO}_{4}$ in lithium-ion batteries. Nanoscale. $\mathbf{5}$, 780-787 (2013).

45. Wang, C. et al. Structural engineering of sulfur-doped carbon encapsulated bismuth sulfide core-shell structure for enhanced potassium storage performance. Nano Res. 14, 3545-3551 (2021).

46. Mehrmohammadi, M. et al. In vivo pulsed magneto-motive ultrasound imaging using high-performance magnetoactive contrast nanoagents. Nanoscale. 5, 11179 (2013).

\section{Acknowledgments}


This work was supported by the National Key Research and Development Program of China [No. 2017YFA0205502], National Natural Science Foundation of China [No. 82072067, 61821002] and the Fundamental Research Funds for the Central Universities.

\section{Competing interests}

The authors declare no competing interests.

\section{Additional information}

Supplementary information The online version contains supplementary material available at https://doi.org/xxx.

Correspondence and requests for materials should be addressed to Ming Ma, Ning Gu or Yu Zhang. 


\section{Supplementary Files}

This is a list of supplementary files associated with this preprint. Click to download.

- SupportingInformationNC220118.docx 